\title{
Actividades creativas, transformaciones urbanas y paisajes emergentes. El caso del casco norte de Sevilla*
}

\author{
Antonio García García \\ agargar1@upo.es \\ Víctor Fernández Salinas \\ Inmaculada Caravaca Barroso \\ Gema González Romero \\ Universidad de Sevilla. Departamento de Geografía Humana \\ salinas@us.es \\ caravaca@us.es \\ gemagonzalez@us.es
}

Universidad Pablo de Olavide. Departamento de Geografía, Historia y Filosofía

\section{Resumen}

La literatura científica sobre las actividades creativas se centra frecuentemente en su capacidad para incidir en la dinámica de ciudades, sobre todo metrópolis y regiones urbanas, y territorios centrales, siendo menos frecuentes los estudios sobre núcleos periféricos. En estos, tales actividades presentan menor capacidad para cambiar tendencias y, también, para manifestarse en el imaginario urbano, entendido tanto desde la perspectiva del paisaje como de las percepciones de los ciudadanos. Este artículo plantea esta perspectiva y parte del axioma de que no es posible entender los nuevos procesos de ciudades menos centrales sin tener en cuenta, aun con una presencia menor, la existencia de las actividades creativas. Todo ello se aplica al estudio de caso del casco norte de Sevilla, ciudad media en el contexto europeo y capital de una región periférica, Andalucía, pero con importantes cambios en sus dinámicas internas durante los años del actual proceso de reestructuración socioeconómica.

Palabras clave: actividades creativas; transformaciones urbanas; centros históricos; paisaje urbano; imaginario urbano.

* Este artículo se integra en dos proyectos de investigación del Plan Nacional Español de $\mathrm{I}+\mathrm{D}+\mathrm{i}$ : Las regiones metropolitanas españolas en la sociedad del conocimiento: tendencias económicas y transformaciones territoriales (ref. COS2009-10888) y Paisajes Patrimoniales de España (ref. CSO2012-39564-C07). 
Resum. Activitats creatives, transformacions urbanistiques i paisatges emergents. El cas del casc nord de Sevilla

La literatura científica sobre les activitats creatives sovint se centra en la capacitat que tenen d'influir en la dinàmica de les ciutats, especialment metròpolis i regions urbanes, i territoris centrals, i són menys abundants els estudis sobre nuclis periferics. En aquests, aquestes activitats tenen menys poder per canviar tendències i, també, per manifestar-se en l'imaginari urbà, entenent-lo tant des de la perspectiva del paisatge com des de les percepcions dels ciutadans. Aquest article planteja aquesta perspectiva i parteix de l'axioma que no es poden entendre els nous processos en aquestes ciutats menys centrals sense tenir en compte, fins i tot amb una presència reduïda, l'existència d'activitats creatives. Tot això s'aplica a l'estudi de cas del casc antic nord de Sevilla, ciutat mitjana en el context europeu i capital d'una regió periferica, Andalusia, però amb canvis significatius en la seva dinàmica interna durant els anys de el procés actual de reestructuració socioeconòmica.

Paraules clau: activitats creatives; transformació urbana; centres històrics; paisatge urbà; imaginari urbà.

Résumé. Activités créatives, transformations urbaines et paysages émergents. Le cas du quartier nord deville historique de Séville

La littérature scientifique sur les activités créatives se concentre souvent sur leur capacité d'influence sur la dynamique des villes, en particulier des métropoles, des régions urbaines, et des territoires centraux, les études étant moins fréquentes sur des lieux périphériques. Pour ces derniers, ces activités présentent moins de possibilités de changer les tendances et de se manifester, aussi, dans l'imaginaire urbain, que ce soit du point de vue du paysage ou de celui des perceptions des citoyens. Cet article propose cette perspective et il part de l'axiome selon lequel il n'est pas possible de comprendre les nouveaux processus dans ces villes moins centrales sans tenir compte, même avec une présence réduite, de l'existence d'activités créatives. Tout cela s'applique à l'étude de cas du quartier nord de la ville historique de Séville, une ville moyenne dans le contexte européen et capitale d'une région périphérique, l'Andalousie, mais présentant des changements importants dans sa dynamique interne au cours des années du processus actuel de restructuration socio-économique.

Mots-clés: activités créatives; centres historiques; transformation urbaine; paysage urbain; imaginaire urbain.

Abstract. Creative activities, urban transformations and emerging landscapes: The case of the northern historic quarter of Seville

The scientific literature on creative activities often focuses on the capacity of such activities to lead the dynamics of cities, particularly in metropolitan areas, urban regions and central territories, with studies on peripheral cores being less frequent. In peripheral cores, these activities have less power to change trends and manifest themselves in the urban imaginary as understood from both the perspective of the landscape and the perceptions of citizens. This article takes this approach based on the axiom that it is not possible to understand the new processes in these less central cities without taking into account the existence of creative activities, despite their scarce presence. This issue is applied to the case study of the northern historic quarter of Seville, a mid-sized, European city and capital of a peripheral region, Andalusia, whose internal dynamics have experienced significant changes during the current socio-economic restructuring process.

Keywords: creative activities; urban transformation; historical quarters; urban landscape; urban imaginary. 


\section{Sumario}

1. Introducción 4. Imaginario, patrimonio y paisaje

2. Creatividad, transformación urbana y paisaje patrimonial de la creatividad a partir de espacios de referencia significativos

5. Conclusiones

3. Contextos, agentes y manifestaciones espaciales de la creatividad en el casco norte de Sevilla

Referencias bibliográficas

\section{Introducción}

La creatividad es un proceso de carácter complejo y, a la vez, un recurso que se materializa en actividades, equipamientos e ideas. Como proceso alienta dinámicas capaces de modificar o reactivar tejidos sociales y también el establecimiento de imágenes reconocibles en diferentes escalas. La creatividad, entendida como la capacidad para generar nuevas ideas y métodos que coadyuven al avance del conocimiento y a los procesos de desarrollo, es una característica que se puede encontrar asociada a cualquier función económica o a fórmulas de expresión social; no obstante, este trabajo se centra en aquellos agentes y, sobre todo, actividades creativas relacionados con el sector cultural; eso sí, entendido este en una perspectiva amplia (UNCTAD, 2008). Los movimientos y las actividades creativas de sesgo cultural interesan en razón de su aptitud para producir o significar lugares, imaginarios y paisajes. En este camino, las nuevas percepciones sobre un determinado espacio, incluso con pocos cambios susceptibles de ser captados por la vista, pueden explicar la cofabricación de lugares y paisajes de la creatividad.

Los estudios sobre los impactos espaciales de la creatividad se vienen centrando en ejemplos urbanos relevantes como nodos del espacio de flujos y redes de las dinámicas creativas globales (Landry, 2000; Costa, 2008) y hacen hincapié en la concentración de la creatividad en las grandes metrópolis occidentales (Florida, 2012) y en aspectos relacionados con la presencia y la distribución de sus agentes y actividades, así como de sus repercusiones en la imagen y en el carácter de zonas urbanas específicas. Buena parte de las políticas urbanas de competitividad se inspiran en la evolución de dichas urbes, pero tal evolución no es fácilmente extrapolable a contextos socioeconómicos distintos o con dificultades para establecer redes y dinámicas como las de aquellas ciudades que ya poseían una tradición competitiva en el marco global: Costa Este estadounidense (Currid, 2007), California (Brinkhoff, 2006), Gran Londres (Freeman, 2007; Knell y Oakley, 2007), Isla de Francia (Baumont y BoiteuxOrin, 2005), etcétera.

En Europa se han analizado numerosos ejemplos de ciudades medias con éxito en dicho marco: Ámsterdam (Gill, 2007), Copenhague (Bayliss, 2007), Dublín (Murphy y Redmond, 2008), Estocolmo (Johansson, 2010), Florencia (Lazzeretti, 2007), Lille (Liegooghe y Lusso, 2010), Lyon (Moriset, 2003)...; pero tanto en este continente como fuera de él son menos conocidas obras que 
Tabla 1. Objetivos y estrategias metodológicas del trabajo

\begin{tabular}{|c|c|c|}
\hline Objetivo principal & Objetivos secundarios & Fases metodológicas \\
\hline \multirow{6}{*}{$\begin{array}{l}\text { Ponderar la proyección espa- } \\
\text { cial de las actividades creati- } \\
\text { vas y la imagen e imaginario } \\
\text { que producen en una ciudad } \\
\text { periférica del contexto global: } \\
\text { el caso de Sevilla y, específi- } \\
\text { camente, su casco norte. }\end{array}$} & $\begin{array}{l}\text { Reflexionar sobre el papel de } \\
\text { las actividades creativas en } \\
\text { ciudades secundarias de con- } \\
\text { textos globales. }\end{array}$ & $\begin{array}{l}\text { Presentación del marco global } \\
\text { de referencia de las trans- } \\
\text { formaciones en este tipo de } \\
\text { ciudades. }\end{array}$ \\
\hline & \multicolumn{2}{|c|}{ Estudio de caso: Casco norte de Sevilla } \\
\hline & Objetivos secundarios & Fases metodológicas \\
\hline & $\begin{array}{l}\text { Identificar procesos y agentes } \\
\text { concernidos por la creatividad } \\
\text { (gentrificación, renovación } \\
\text { urbana, grupos socio-econó- } \\
\text { micos específicos...). }\end{array}$ & $\begin{array}{l}\text { Descripción de procesos y } \\
\text { presentación de agentes. }\end{array}$ \\
\hline & $\begin{array}{l}\text { Conocer las pautas de } \\
\text { distribución de los vectores } \\
\text { visibles de la creatividad y } \\
\text { los espacios de referencia } \\
\text { (nodos, ejes y ámbitos) que } \\
\text { propician. }\end{array}$ & $\begin{array}{l}\text { Análisis de la distribución } \\
\text { de las actividades creativas } \\
\text { y sus espacios de referencia. } \\
\text { Reconocimiento de otros } \\
\text { vectores visibles. }\end{array}$ \\
\hline & $\begin{array}{l}\text { Analizar cualitativamente los } \\
\text { imaginarios/paisajes y signifi- } \\
\text { cados de la creatividad a par- } \\
\text { tir de espacios de referencia } \\
\text { significativos. }\end{array}$ & $\begin{array}{l}\text { Selección y análisis de luga- } \\
\text { res, ejes y ámbitos repre- } \\
\text { sentativos de las dinámicas } \\
\text { creativas. }\end{array}$ \\
\hline
\end{tabular}

Fuente: elaboración propia.

expresen el impacto de la creatividad en ciudades de la misma escala pero con menor protagonismo, o sin él, en el contexto socioeconómico global.

Con una mayor concreción escalar, los centros históricos resultan un ámbito de estudio especialmente interesante para esta perspectiva, ya que, más allá de las distintas fórmulas de protección de las que son depositarios, modifican sus espacios públicos y construidos, desarrollan usos y atraen actores (residentes, comerciantes, visitantes...) que en conjunto denotan y connotan un paisaje cambiante.

En relación con todo lo anterior, este trabajo se propone un objetivo principal que se acompaña de varios objetivos secundarios, a partir de los cuales se plantean distintas estrategias metodológicas (ver Tabla 1).

La singularidad de las actividades creativas y sus manifestaciones socioespaciales precisan fuentes de información directas y específicas. A este respecto, y además de las referencias bibliográficas que se aportan al final del artículo, la información manejada procede del trabajo de campo sistemático sobre todo el sector analizado y que se completó durante el otoño de 2013. Este ha generado un inventario de manifestaciones espaciales de creatividad; entre ellas se ha recogido información exhaustiva sobre locales y lugares en los que se desarrollan actividades creativas de carácter muy diverso (diseño arquitectónico, carte- 
lería, creación de escenarios urbanos, ambientes socioculturales específicos...). La recogida de esta información se ha sistematizado a partir de fichas en las que, además de la fecha y los aspectos generales de cada registro (ubicación, imágenes fotográficas e interés que motiva su consideración), se ha segregado el universo de registros en razón de: $a$ ) la ubicación en espacio público o privado y b) la actividad, la imagen o el proceso urbano a los que se asocia. Con el tratamiento de estos datos se han identificado los nodos en los que se concentran los aspectos relacionados con las actividades creativas, la transformación de la ciudad y sus nuevos paisajes emergentes. Las concentraciones de nodos han permitido diferenciar entre lugares (escenarios acotados), ejes (calles) y ámbitos (sectores urbanos) como los espacios en los que se están percibiendo la renovación y los nuevos significados de la parte de la ciudad analizada.

Esta información se ha cualificado a partir de fuentes complementarias: tanto de la consulta de páginas web relacionadas con los distintos agentes del sector considerado, como de la entrevista en profundidad a quince agentes concernidos de forma diferencial por los procesos objetos de este trabajo.

\section{Creatividad, transformación urbana y paisaje patrimonial}

\subsection{Cambios urbanos vinculados a la creatividad}

Creatividad y ciudad son dos realidades que se asumen de forma casi automática, si bien la concreción de esta relación cubre distintas facetas; entre otras: el reconocimiento de la creatividad como proceso sociocultural (Landry, 2000; Berdoulay, 2002), su materialización en actividades y recursos de interés para el desarrollo urbano y territorial (Cook y Lazzaretti, 2008; Pratt, 2008; García, et al., 2012) o la promoción de equipamientos, eventos y servicios creativos. Estos últimos tienen una presencia notable en el debate sobre las transformaciones urbanas vinculadas a políticas públicas (Gil, 2010; Paül, 2013). En un primer nivel de reconocimiento internacional aparecen aquellas ciudades cuya visibilidad global está asociada a propuestas creativas ambiciosas por sus contenidos, su carácter innovador o, con un sentido más negativo, la construcción de megaproyectos. Estos equipamientos, eventos o focos de actividad creativa suelen plasmarse con notoriedad en la trama urbana, pero destacan aquellos que, además de visibilidad, favorecen la transformación de zonas centrales desmanteladas y/o degradadas.

Dada la capacidad de transformación urbana que tienen los recursos culturales y creativos, también han ganado presencia actuaciones más modestas pero más integradas, capaces de favorecer procesos de renovación urbana, lo cual es especialmente interesante en antiguos ámbitos industriales desmantelados que han ganado centralidad como resultado de los procesos de expansión metropolitana (París - La Villette, Barcelona 22@...). En cualquier caso, a priori, serán más viables aquellas actuaciones que estén sustentadas en recursos precedentes, que se integren en planes urbanos no sectoriales o que atiendan a los diferentes agentes implicados en los procesos de reconversión o promoción (Evans, 2009), de lo que se podría deducir, por otro lado, que las estrategias de 
arriba abajo no serán causa suficiente para la presencia de actividades y agentes creativos que puedan operar y acompañar procesos de transformación urbana.

Para este artículo resulta de interés el papel activo que pueden tener las actividades creativas en los cambios sociourbanísticos de tramas concretas de ciudades que no están fuertemente enraizadas en el mercado global. Se trata, pues, no solo de poner la atención en un tipo de ciudades, sino también de concebir la creatividad desde una escala intraurbana, lo que permite incorporar otras líneas de argumentación que plantean nuevos modelos de emergencia creativa en la que cobran importancia los procesos no planificados y que, a menudo, tienen como protagonistas a pequeños grupos o individuos que desarrollan acciones con potencial para transformar sus barrios y generar además movimientos (término más genérico que actividades) creativos (Jacobs, 2004).

Una mirada a la inversa sobre la relación entre creatividad y ciudad implicaría aceptar que determinados componentes urbanos, culturales y sociopolíticos favorecen la emergencia y la consolidación de imágenes, paisajes, lugares y actividades de la creatividad (Cassián, 2012). A tal respecto Jordi Borja (2008) plantea cómo las zonas de la ciudad especialmente sensibles a los procesos de transformación inducidos por actividades creativas son aquellas en las que se dan condiciones como: el carácter mixto de sus funciones, el mantenimiento de un carga residencial variada, la comunicación complementaria con otras centralidades, la existencia de un espacio público animado, o la presencia de referentes identitarios, entre otros. Son condiciones reseñables igualmente para un discurso más amplio sobre los recursos y atractivos de la ciudad, pero, en este caso, tienen la particularidad de ser especialmente valorados por las clases creativas (Florida, 2005) que afianzan en ellos sus motivaciones y asumen sus inconvenientes. Resulta ilustrativa la dialéctica entre la transformación del perfil socioeconómico de estas tramas urbanas y la emergencia de dinámicas revisadas de reconocimiento barrial (Lloyd, 2010).

\subsection{Paisajes patrimoniales / paisajes emergentes}

En los últimos años, los trabajos sobre paisajes patrimoniales han adquirido una gran relevancia, tanto en lo que atañe a su visibilidad (Maderuelo, 2010; Skazzosi, 2007) como en lo concerniente a su aplicación a distintas escalas de percepción (Galimberti, 2013). Particularmente interesante es el debate sobre los paisajes cotidianos, en los que la dimensión patrimonial se mide por su capacidad para generar identidad en las comunidades que los habitan. Esta línea lleva a considerar que todos los paisajes del mundo habitado son patrimoniales, en tanto que todos son fuente potencial de identidad para sus habitantes (Ojeda, 2013). Desde el punto de vista institucional, dos organismos han sido básicos en la conceptualización de este término desde una perspectiva internacional: Unesco, que incorpora desde 1992 la categoría de paisaje cultural a la Lista del Patrimonio Mundial (Aplin, 2007) y, en 2000, el Consejo de Europa a través del Convenio Europeo del Paisaje. 
La primera establece una denominación que ha tenido amplio calado: $p a i-$ saje cultural, aunque desde una perspectiva de ortodoxia conceptual plantea problemas, por cuanto todos los paisajes, en tanto que son percibidos por la mirada humana, son culturales; por lo que es preferible utilizar la expresión paisajes patrimoniales. El Convenio Europeo del Paisaje, por su parte, plantea una visión global respecto al paisaje; lo entiende como producto de la percepción de la población y lo extiende a la totalidad del territorio. En relación con los conceptos clave de este convenio, establece que la primera acción, la protección, se vincula primordialmente a paisajes de especial relevancia patrimonial. Por su lado, el Landscape Character Assessment (LCA) ofrece una perspectiva interescalar y otros aspectos que posibilitan la lectura e interpretación compleja del paisaje, de modo que también aquellos de significado patrimonial pueden ser entendidos en diversas escalas territoriales, incluso en escenarios urbanos o ámbitos muy acotados.

Por su parte, se ha analizado poco la relación entre creatividad y patrimonio, cuando, sin duda, este no solo se expresa a partir de realidades del pasado, sino, sobre todo, a partir de su significado presente y de su capacidad para establecer recursos para el futuro. Este discurso es de especial interés en contextos tales como los centros históricos, en los que la búsqueda de nuevas funcionalidades que los mantengan vivos pasa por políticas de integración de residencia y actividad. En este sentido, las actividades creativas son un interesante campo de experimentación para alcanzar nuevos significados urbanos, nuevas autenticidades y, en general, nuevos valores que los mantengan como espacios vivos y no repositorios del pasado. Su identidad se encuentra en las formas de los espacios públicos y privados, en las funciones que en ellos se desarrollan, en la percepción colectiva de las nuevas dinámicas de transformación social y urbana, y en los paisajes que generan (Nogué, 2010).

\section{Contextos, agentes y manifestaciones espaciales de la creatividad en el casco norte de Sevilla}

\section{1. ¿Por qué Sevilla y su casco norte?}

Sevilla es la capital de una región periférica en el primer mundo, circunstancia estructural a la que se suma un contexto de crisis económica internacional. No obstante, en determinadas escalas, actividades y lecturas, sigue manifestando una gran riqueza y capacidad de generar realidades nuevas. Estas realidades, no siempre fáciles de entender, están influidas por cuestiones como la capitalidad de una extensa comunidad autónoma, su situación geoestratégica en el extremo suroccidental de la Unión Europea, el volumen de su población metropolitana - en torno al millón y medio de personas - y la transformación física y socioeconómica que ha experimentado durante el último cuarto del siglo xx.

En el caso particular de las actividades creativas se evidencia que, aunque su desarrollo no resulta comparable a otras ciudades del contexto internacional, sí pueden ofrecer una interesante información sobre su comportamiento en contextos periféricos (Andalucía, España) de territorios centrales (Unión Europea). 
Como se ha puesto de manifiesto en otros trabajos recientes sobre el contexto andaluz (Caravaca et al., 2011; 2013), Sevilla es un nodo de concentración de actividades creativas y, dentro de la ciudad, el casco norte muestra una posición relevante en cuanto a la presencia y diversidad de este tipo de actividades.

No menos importante es redimensionar estas actividades en la medida que son resultado y palanca de procesos y transformaciones urbanas de distinto signo: ya sea desde el punto de vista de nuevos elementos que se distribuyen por estas tramas urbanas, de procesos más profundos de transformación espacial y socioeconómica, o bien de generación de imágenes cada vez más potentes e identificables.

En el caso del casco norte de Sevilla es muy evidente la interrelación entre dinámicas creativas emergentes y otros componentes urbanos. En la medida que se conozcan las claves de este sector podrá ser interpretada la coexistencia de movimientos creativos que surgen de forma no planificada, con aquellos que son producto de iniciativas de carácter institucional. Los primeros, tan irregulares como resilientes, buscan distintas fórmulas de interrelación. Las segundas se apoyan en las sinergias preexistentes y, a veces, llegan incluso a realimentarlas. Sin embargo, en el caso de Sevilla, estas iniciativas institucionales, fundamentalmente del Ayuntamiento y de la Junta de Andalucía, no están adecuadamente coordinadas, no suelen tener una continuidad suficiente en el tiempo y están muy sometidas a los compromisos presupuestarios de estas instituciones. Por ello, la valoración de esta sinergia es difícil y requeriría trabajos que trascienden el objeto de este estudio.

A todo ello se debe unir el hecho de que la crisis afecta de forma diferencial e inesperada a los distintos ámbitos urbanos, pudiendo provocar el surgimiento de alternativas radicadas en peculiaridades zonales, sin que por ello sigan un patrón unívoco de aparición y desarrollo.

\subsection{Procesos y agentes concernidos por la creatividad en el casco norte de Sevilla}

La conformación durante la segunda mitad del siglo xx de múltiples centralidades urbanas - a la par que se consolidaron ámbitos de sesgo periférico no solo en los bordes urbanos, sino también en zonas centrales- avanza en los últimos decenios hacia realidades más complejas en las que la centralidad, sea cual sea el ámbito en la que se halle, lleva en sí misma rasgos de periferia y viceversa. Como en otras muchas ciudades del mundo, la reafirmación y la recomposición del tejido urbano de significado cultural-creativo en Sevilla encuentra singulares posibilidades y estímulos en las tramas en las que esta nueva dialéctica manifiesta mayor empaque.

El casco norte es un ámbito de gran complejidad, tanto en su origen como en su realidad actual. Convertido en un ámbito obrero en los últimos decenios del XIx, frente al sur de la ciudad histórica que se significa como espacio próspero, moderno y de mayor nivel económico y cultural, prolonga este carácter hasta más allá de la mitad del siglo xx (González, 2001). Pese a todo, en los 
años setenta presentaba todavía una gran variedad de situaciones: desde barrios en su sector suroccidental (San Vicente) que mantenían un carácter señorial, hasta otros físicamente deteriorados y con claros síntomas de marginalidad (especialmente San Luis y entorno de la Alameda). Entre ambos extremos aparecían situaciones intermedias, predominando los niveles modestos e intercalados con algunas actividades artesanales e industriales (Almuedo, 1996).

En los últimos decenios del siglo pasado se pueden señalar acciones diversas que contribuyeron a redefinir este sector. Entre ellas, la Exposición Universal de 1992, la centralidad ganada por la gran expansión metropolitana de Sevilla, la rehabilitación como Parlamento de Andalucía del antiguo hospital de las Cinco Llagas, o distintas iniciativas municipales sobre parte del caserío tradicional. No obstante, el más intenso motor de la transformación física y social del interior del casco norte fue el proyecto europeo URBAN, desarrollado en la segunda mitad de los años noventa. Este se centró en un importante sector que abarcaba ámbitos bien distintos entre sí (Alameda, Feria o San Luis) y, si bien se aplicó fundamentalmente a la renovación de infraestructuras, espacios públicos y algunas dotaciones, supuso de facto una expulsión masiva de clases modestas y marginales (Cantero et al., 1999). A ello contribuyó una coyuntura de fuerte especulación urbana que encontró en este sector renovado un importante campo para recuperar e incrementar las plusvalías de sus solares, activando un sensible proceso de gentrificación (Díaz, 2014).

Todo esto generó un importante movimiento contestatario (Barber et al., 2006) y dio lugar a una imagen nueva del sector. Atraídas en parte por el ambiente alternativo y, más tarde, por el afianzamiento de la Alameda de Hércules como lugar de encuentro y ocio, un importante volumen de personas fue alquilando o comprando apartamentos, gestándose un nuevo carácter para esta zona.

Con la aparición de la crisis actual, no solo se consolidan los procesos antes apuntados, sino que se suman iniciativas urbanísticas de promoción pública enfocadas a la recuperación de espacios singulares, como la Alameda de Hércules, más dirigidas a la promoción de la imagen de la ciudad que a la generación de dinámicas inclusivas locales. A su vez, favorecidas por los nuevos perfiles culturales y, en muchos casos, por la propia presencia de espacios físicos que facilitan su asentamiento (naves, corralones artesanos y antiguos espacios fabriles irregularmente distribuidos por el sector, junto a otro tipo de locales con precios de alquiler y compra más accesibles que en otras zonas intramuros), empiezan a hacerse visibles actividades creativas que refuerzan la singularidad de este sector del casco histórico y que responden a tipos muy diversos, que abarcan desde la artesanía tradicional a servicios creativos contemporáneos, pasando por distintas fórmulas de asociacionismo o de activismo okupa.

En paralelo a estas actividades aflora la presencia de personas cercanas a las citadas clases creativas, ligadas cultural, sentimental e incluso laboralmente a las nuevas actividades socioeconómicas de este ámbito. Este colectivo decide residir en él atraído por sus nuevas dinámicas, y reproduce impactos propios de los procesos convencionales de gentrificación; pero también desarrolla dinámicas de identificación y apropiación de sus barrios, fundamentales en la 


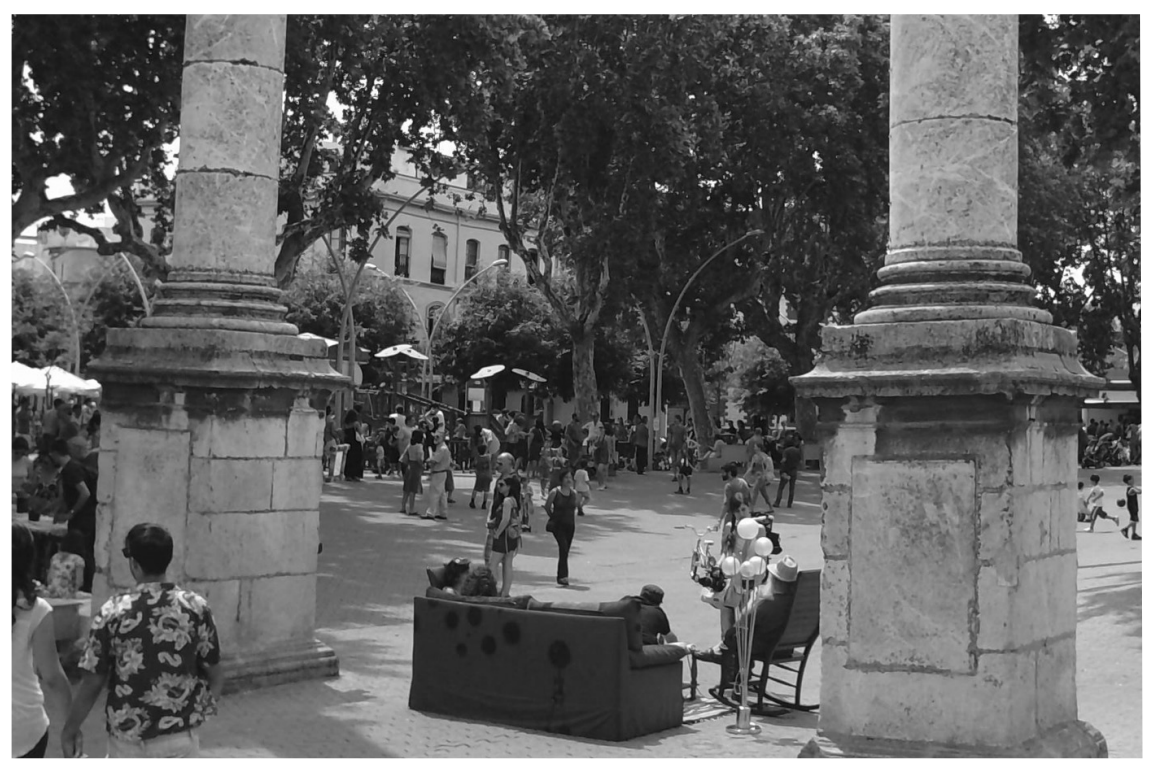

Figura 1. Acto reivindicativo en el andén central de la Alameda de Hércules - utilizando el espacio público como casa propia - frente a la propuesta construcción de un aparcamiento.

Fuente: los autores (julio 2013).

animación de sus espacios públicos, en sus actividades sociales o en el desarrollo de la actividad comercial.

De la suma de iniciativas públicas, operaciones de regeneración urbana, intereses especulativos y dinámicas informales, resulta un espacio urbano de gran complejidad social, en el que las aspiraciones de distintos grupos e instituciones se contraponen y abonan el campo para procesos sociales y económicos que no están presentes en otras zonas de Sevilla. Resultan ilustrativas iniciativas entre lo lúdico, lo identitario y lo reivindicativo, en las que confluyen de forma asimétrica los viejos y los nuevos agentes del casco norte. Representaciones simbólicas como estas son parte esencial del imaginario de este sector (Figura 1).

Si bien este rompecabezas urbano dificulta el reconocimiento de pautas de distribución espacial, existen suficientes razones fenomenológicas entre los espacios residenciales, comerciales y públicos de los distintos sectores del casco norte y el vecindario que marca las pautas en ellos, para poder esbozar un esquema interpretativo (Figura 2).

En la figura 2 cabe distinguir entre las tramas occidentales y meridionales del casco norte y aquellas centrales, septentrionales y orientales. En las primeras (correspondientes con la mayor parte de los barrios de San Vicente y de Encarnación-Regina, así como el sector más occidental del de San Lorenzo y una parte del de Santa Catalina) predomina una estructura sociourbanística consolidada en los últimos decenios, o que incluso en determinadas zonas ha 


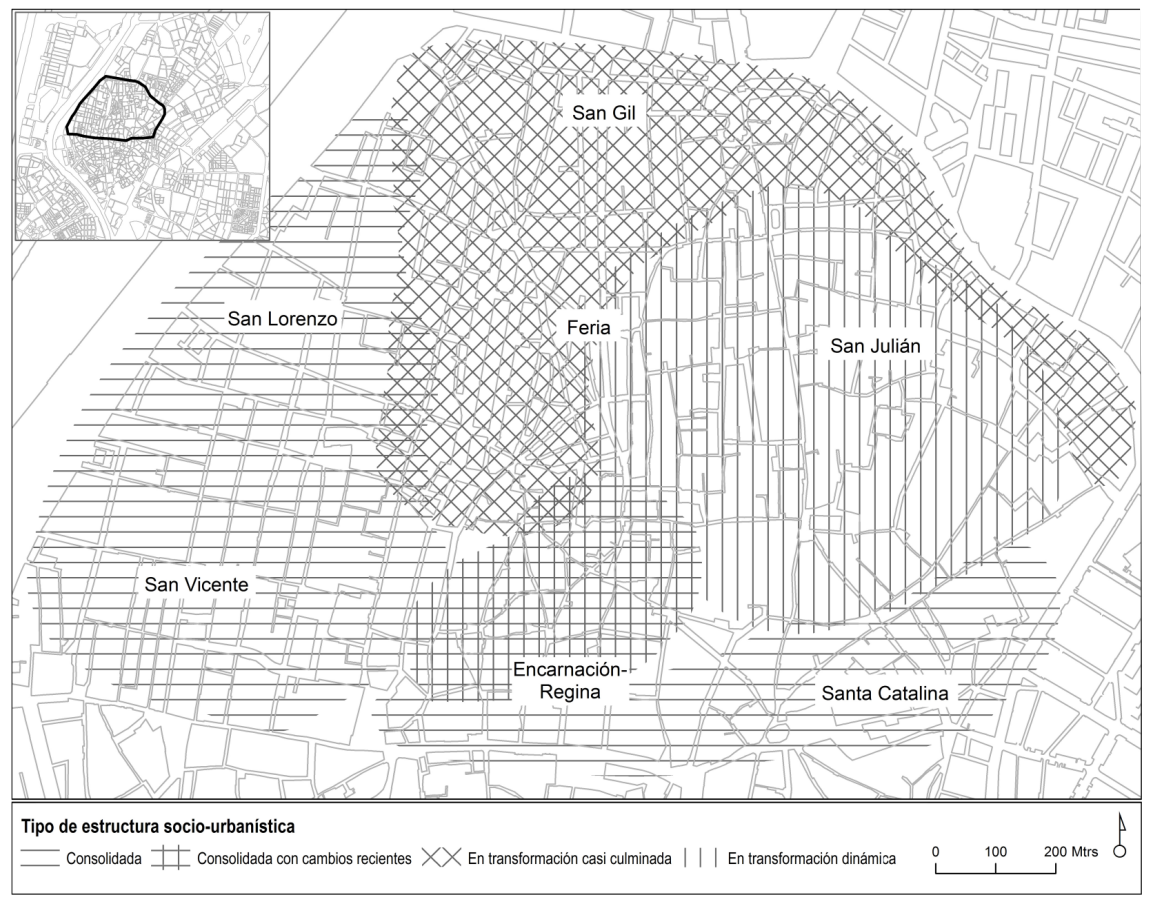

Figura 2. Síntesis de dinámicas socioespaciales del casco norte.

Fuente: elaboración propia.

sido objeto de cambios en el plano residencial —social y constructivo- ya suficientemente asumidos.

Por su parte, los barrios de Feria, San Gil, San Julián y la Alameda de Hércules son aquellos en los que las dinámicas y tensiones sociourbanísticas son más patentes, sea por su celeridad o por su vigencia. Este es el ámbito en el que ha habido un mayor número de modificaciones en el espacio construido y en la estructura socioeconómica, incluyendo la pluralidad de perfiles mencionados. Ahora bien, mientras en buena parte del espacio de aplicación del Plan URBAN (entornos de Alameda de Hércules y calles Feria o San Luis) estos cambios han sido muy intensos y en la actualidad parecen estar culminados, las modificaciones de las estructuras urbanas de barrios como San Julián y la mitad oriental de Feria son, hoy en día, muy dinámicas.

\subsection{Pautas de distribución espacial de las actividades creativas: lugares, ejes $y$ ámbitos}

La visibilidad de las actividades creativas puede definirse en el plano urbano a partir de los ya citados nodos, lugares, ejes y ámbitos (Figura 3). Los primeros, 


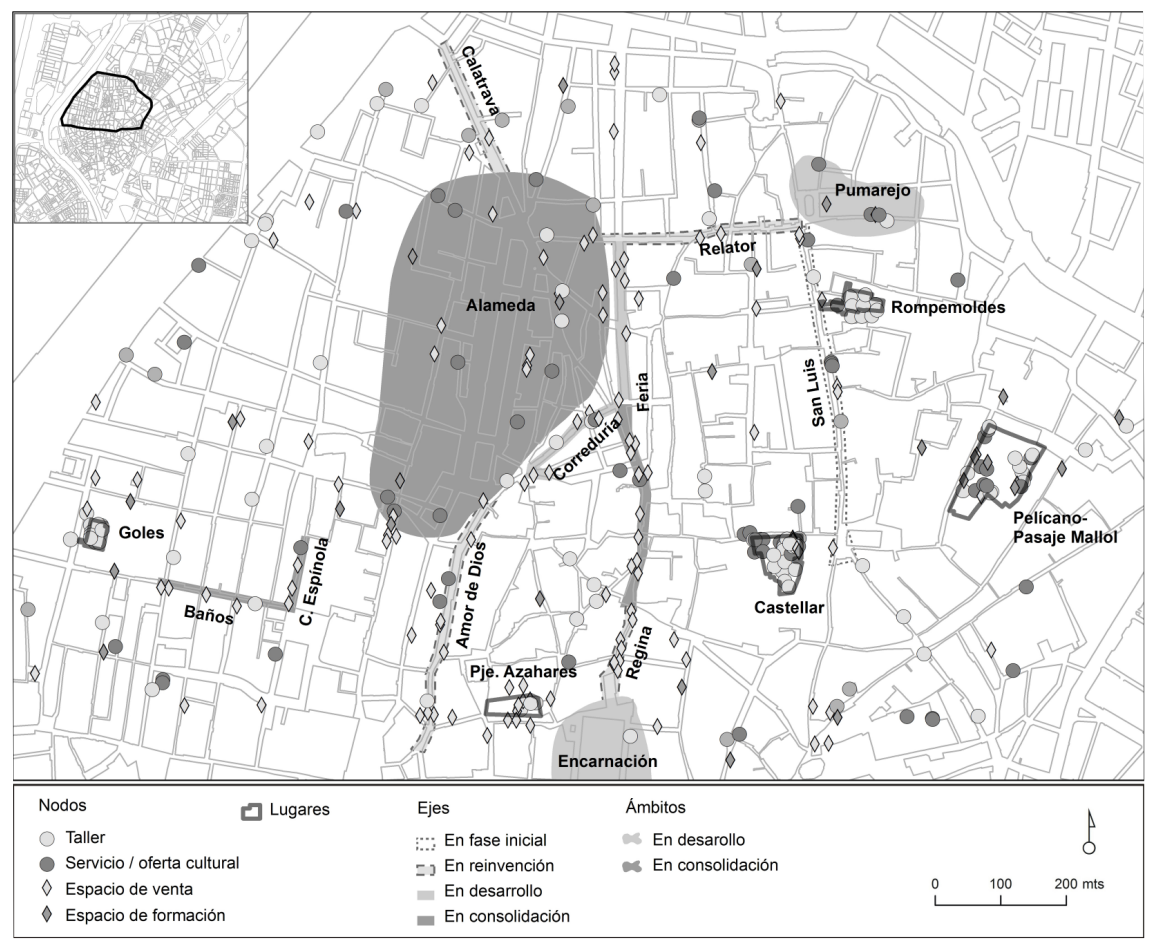

Figura 3. Distribución de nodos, lugares, ejes y ámbitos creativos en el casco norte.

Fuente: elaboración propia.

los nodos, señalan la percepción física de actividades creativas (generalmente locales comerciales, arquitectura de diseño, etcétera) y se distribuyen aleatoriamente por el casco norte.

Los lugares son reconocibles por la concentración de tales nodos en espacios acotados, por su carácter de espacios de sociabilidad y por el valor simbólico de la imagen creativa que proyectan. Dichos lugares tienen orígenes muy distintos — desde los que desarrollan actividades artesanales desde hace decenios hasta otros de muy reciente concreción-y su presencia actual es mayor en el sector oriental de la parte del casco histórico objeto de estudio.

Los ejes son vías comerciales muy consolidadas en las que se dispone un buen número de nodos (calles Feria-Regina, Amor de Dios - Correduría o Baños - Cardenal Espínola). También se consideran como ejes espacios con una concentración menor de nodos, aunque con una gran potencia en el imaginario urbano sevillano: se trata de calles como Relator, San Luis o Calatrava, u otras que podrían considerase emergentes como San Hermenegildo.

Por su parte, no resulta tan evidente la formación de ámbitos (sectores urbanos de escala más compleja y extensa que los lugares) en función del 
asentamiento inmueble de actividades creativas, pero sí por el significado de estas alrededor de algunos espacios públicos urbanos muy connotados en zonas como la Alameda de Hércules o las plazas del Pumarejo y de la Encarnación (Figura 3).

Si se atiende a la naturaleza de las actividades creativas identificadas, resulta muy clara la importancia porcentual que tienen los establecimientos de venta frente a aquellos en los que se produce o se ofrece un servicio cultural o creativo. Como ya se ha apuntado, en el casco norte conviven no solo distintos tipos de actividades creativas, sino también una variada oferta dentro de cada uno de ellos. Así, talleres, espacios escénicos o establecimientos de perfil tradicional alternan con otros con propuestas más contemporáneas, tanto estéticas como de funcionamiento y de forma de entender el producto creativo. Además surgen otros locales difícilmente catalogables en términos convencionales: espacios multifuncionales, empresas del llamado coworking, cooperativas, etcétera.

En razón de la escala de análisis, estos matices cualitativos se desarrollan en el siguiente apartado atendiendo a algunos de los vectores visibles de la creatividad de la trama urbana analizada y que proyectan su singularidad en el conjunto de la ciudad. No obstante, cabe señalar que las fórmulas más novedosas de actividad creativa tienden a concentrase en las tramas centrales y orientales, aquellas más dinámicas aunque en distintos estadios de consolidación o revisión de sus funciones y actividades.

\section{Imaginario, patrimonio y paisaje de la creatividad a partir de espacios de referencia significativos}

Considerando los espacios urbanos en los que se visualizan mejor las actividades creativas (Figura 3) y las características que particularizan a cada uno de ellos, se han seleccionado varios casos a partir de los que se puede, con una escala de detalle, construir la narración de los imaginarios, patrimonios y paisajes de la creatividad en el casco norte (Tabla 2).

\subsection{Lugares}

\section{a) Corralón de calle Goles}

En el interior del número 48 de la calle Goles (Figura 4), al que se accede por un pasadizo, aparece un corralón de artesanos estructurado en dos pequeñas calles paralelas unidas por otra perpendicular. Este corralón posee una larga tradición creativa de corte tradicional y en él se percibe la voluntad de ofrecer una imagen digna. La forma recuerda con bastante exactitud a la que ofrecía en decenios anteriores y los cambios que se han producido en las actividades son más bien escasos. Allí desarrollan su trabajo artistas y artesanos (imagineros y orfebres, fundamentalmente) relacionados con la Semana Santa sevillana y de otras localidades, pero también aparecen otras actividades, como el estudio de un pintor, que asimismo imparte clases, o un taller de restauración. El patio muestra un trasiego constante aunque de baja intensidad. Se puede afirmar 
Tabla 2. Aspectos básicos de los lugares, ejes y ámbitos de creatividad seleccionados

\begin{tabular}{|c|c|c|c|c|c|}
\hline \multicolumn{2}{|c|}{ Casos } & Forma & Función & Animación e identidad & Significado \\
\hline \multirow{3}{*}{ 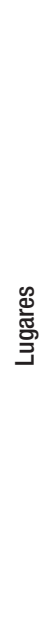 } & $\frac{\mathscr{J}}{0}$ & $\begin{array}{l}\text { — Visibilidad de la } \\
\text { dinámica creativa } \\
\text { media }\end{array}$ & $\begin{array}{l}\text { - Artesanal } \\
\text { - Actividades forma- } \\
\quad \text { tivas }\end{array}$ & $\begin{array}{l}\text { — Animación media } \\
\text { — Identidad definida, } \\
\text { no marginal } \\
\text { — La actividad se } \\
\text { reconoce también } \\
\text { sensorialmente }\end{array}$ & $\begin{array}{l}\text { - Paisaje patrimonial } \\
\text { de corte tradicional } \\
\text { — Mantenimiento del } \\
\text { carácter patrimonial }\end{array}$ \\
\hline & 읋 & $\begin{array}{l}\text { — Diseño exterior par- } \\
\text { ticular } \\
\text { — Visibilidad de la } \\
\text { dinámica creativa } \\
\text { media }\end{array}$ & $\begin{array}{l}\text { - Artesanal } \\
\text { - Lugar de encuentro } \\
\text { - Actividades forma- } \\
\quad \text { tivas } \\
\text { - Oferta cultural }\end{array}$ & $\begin{array}{l}\text { - Continua presencia } \\
\text { humana } \\
\text { - Identidad nueva } \\
\text { (artesanal y creativa) } \\
\text { - Bicicletas }\end{array}$ & $\begin{array}{l}\text { - Apropiación simbóli- } \\
\text { ca del valor singular } \\
\text { (toque creativo) } \\
\text { — Riqueza y variedad } \\
\text { integrada de usos y } \\
\text { significados }\end{array}$ \\
\hline & 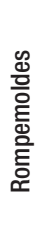 & $\begin{array}{l}\text { - Arquitectura con } \\
\text { pretensiones } \\
\text { - Diseño de locales } \\
\text { - Diseño exterior par- } \\
\text { ticular } \\
\text { — Visibilidad de la diná- } \\
\text { mica creativa alta }\end{array}$ & $\begin{array}{l}\text { - Residencial } \\
\text { - Artesanal } \\
\text { - Comercial }\end{array}$ & $\begin{array}{l}\text { - Sin identidad defi- } \\
\text { nida } \\
\text { - Bicicletas }\end{array}$ & $\begin{array}{l}\text { - Interés de apropia- } \\
\text { ción de los artesanos } \\
\text { del lugar y su } \\
\text { carácter }\end{array}$ \\
\hline \multirow[b]{2}{*}{$\stackrel{\mathscr{d}}{\stackrel{d}{H}}$} & 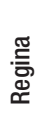 & $\begin{array}{l}\text { - Espacio peatonal } \\
\text { — Diseño de locales } \\
\text { — Visibilidad de la diná- } \\
\text { mica creativa alta }\end{array}$ & $\begin{array}{l}\text { - Comercial } \\
\text { - Hostelería } \\
\text { - Oferta cultural }\end{array}$ & $\begin{array}{l}\text { — Lugar de tránsito } \\
\text { — Sin identidad defi- } \\
\text { nida }\end{array}$ & $\begin{array}{l}\text { — Proyección exterior } \\
\text { — Riqueza y variedad } \\
\text { de usos }\end{array}$ \\
\hline & 丞 & $\begin{array}{l}\text { - Arquitectura con } \\
\text { pretensiones } \\
\text { — Visibilidad de la } \\
\text { dinámica creativa } \\
\text { baja }\end{array}$ & $\begin{array}{l}\text { - Comercial } \\
\text { - Hostelería } \\
\text { - Oferta cultural }\end{array}$ & $\begin{array}{l}\text { — Lugar de tránsito } \\
\text { — Sin identidad defi- } \\
\text { nida }\end{array}$ & $\begin{array}{l}\text { - Revisión del sig- } \\
\text { nificado de una } \\
\text { calle en proceso de } \\
\text { cambio sin identidad } \\
\text { definida }\end{array}$ \\
\hline \multirow[t]{2}{*}{ 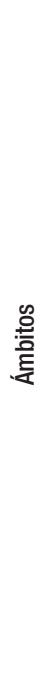 } & 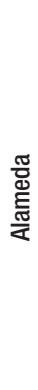 & $\begin{array}{l}\text { — Espacio peatonales } \\
\text { — Arquitectura con } \\
\text { pretensiones } \\
\text { — Diseño de locales } \\
\text { — Diseño espacio } \\
\text { público } \\
\text { — Diseño exterior } \\
\text { particular } \\
\text { — Visibilidad de la } \\
\text { dinámica creativa } \\
\text { alta }\end{array}$ & $\begin{array}{l}\text { - Residencial } \\
\text { - Hostelería } \\
\text { - Institucional } \\
\text { - Lugar de encuentro } \\
\text { - Oferta cultural }\end{array}$ & $\begin{array}{l}\text { - Continua, hetero- } \\
\text { génea y cambiante } \\
\text { presencia humana } \\
\text { — Policía } \\
\text { — Lugar de tránsito } \\
\text { — Identidad nueva } \\
\text { (usos y usuarios) } \\
\text { — Manifestaciones } \\
\text { explícitas de apro- } \\
\text { piación del espacio } \\
\text { público } \\
\text { - Bicicletas }\end{array}$ & $\begin{array}{c}\text { — Proyección exterior } \\
\text { — Apropiación simbóli- } \\
\text { ca del valor singular } \\
\text { y no convencional } \\
\text { (toque esnob) } \\
\text { — Configuración de un } \\
\text { paisaje patrimonial } \\
\text { - Riqueza y variedad } \\
\text { integrada de formas, } \\
\text { usos y significados }\end{array}$ \\
\hline & 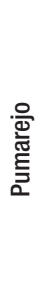 & $\begin{array}{l}\text { — Visibilidad de la } \\
\text { dinámica creativa } \\
\text { media }\end{array}$ & $\begin{array}{l}\text { - Hostelería } \\
\text { - Lugar de encuentro } \\
\text { — Actividades forma- } \\
\quad \text { tivas } \\
\text { - Oferta cultural }\end{array}$ & $\begin{array}{l}\text { - Reivindicación } \\
\text { - Continua presencia } \\
\text { humana } \\
\text { - Identidad mixta } \\
\text { - Manifestaciones } \\
\text { explícitas de apro- } \\
\text { piación del espacio } \\
\text { público } \\
\text { - Bicicletas }\end{array}$ & $\begin{array}{l}\text { - Proyección exterior } \\
\text { — Apropiación simbóli- } \\
\text { ca del valor singular } \\
\text { (toque alternativo) } \\
\text { - Configuración de un } \\
\text { paisaje patrimonial } \\
\text { - Riqueza y variedad } \\
\text { integrada de usos y } \\
\text { significados }\end{array}$ \\
\hline
\end{tabular}

Fuente: elaboración propia. 


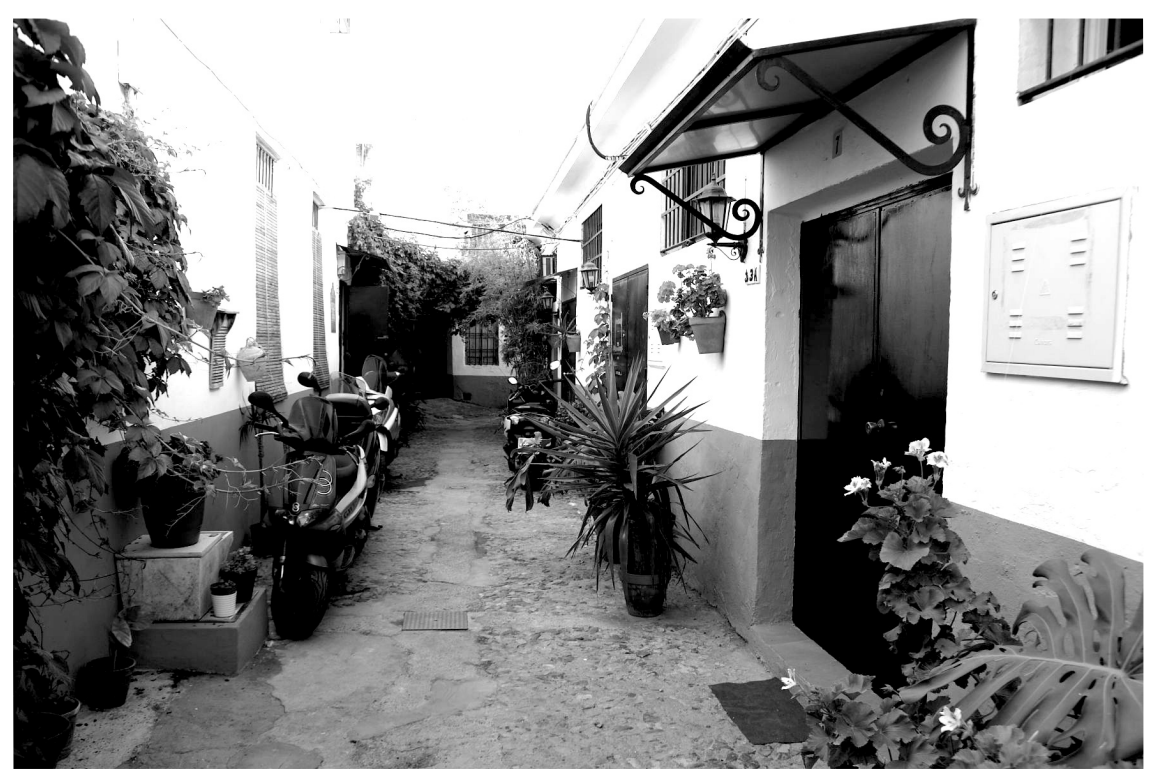

Figura 4. Calle interior del corralón de Goles.

Fuente: los autores (septiembre 2013).

que posee una identidad definida y que las actividades, no solo por la información y forma de los locales, también se reconocen por otras vías sensoriales (sonidos, olores...).

La visibilidad en el paisaje urbano del carácter creativo de estas actividades es casi nula desde el exterior del inmueble y media-baja una vez en el interior. Se trata de una pieza que configura un paisaje patrimonial de tipo interno y que proyecta en el presente los valores culturales de actividades creativas del patrimonio inmaterial tradicional (Figura 4).

\section{b) Corralón de la plaza del Pelícano}

El loteamiento de grandes parcelas procedente de la desamortización decimonónica ha conformado un interesante paisaje industrial interior que desde hace años está reinventando su contenido. Entre las piezas que configuran este sector, la más extensa y variada es el gran corralón del número 4 de la plaza del Pelícano ${ }^{1}$. Se trata de una amplia parcela, perteneciente a una sola dueña, y está estructurado por dos calles de mediana longitud que se unen a la que, con una forma ligeramente irregular, da acceso al conjunto desde la plaza (Figura 5). Su imagen, salvo en detalles, continúa muy cercana a la que ha presentado durante buena parte del siglo pasado, cuando se dedicaba mayoritariamente a talleres de

1. El conjunto lo completa otro corralón al que se accede desde el pasaje Mallol, y algunas naves anexas, como la de la cooperativa creativa Tramallol. 


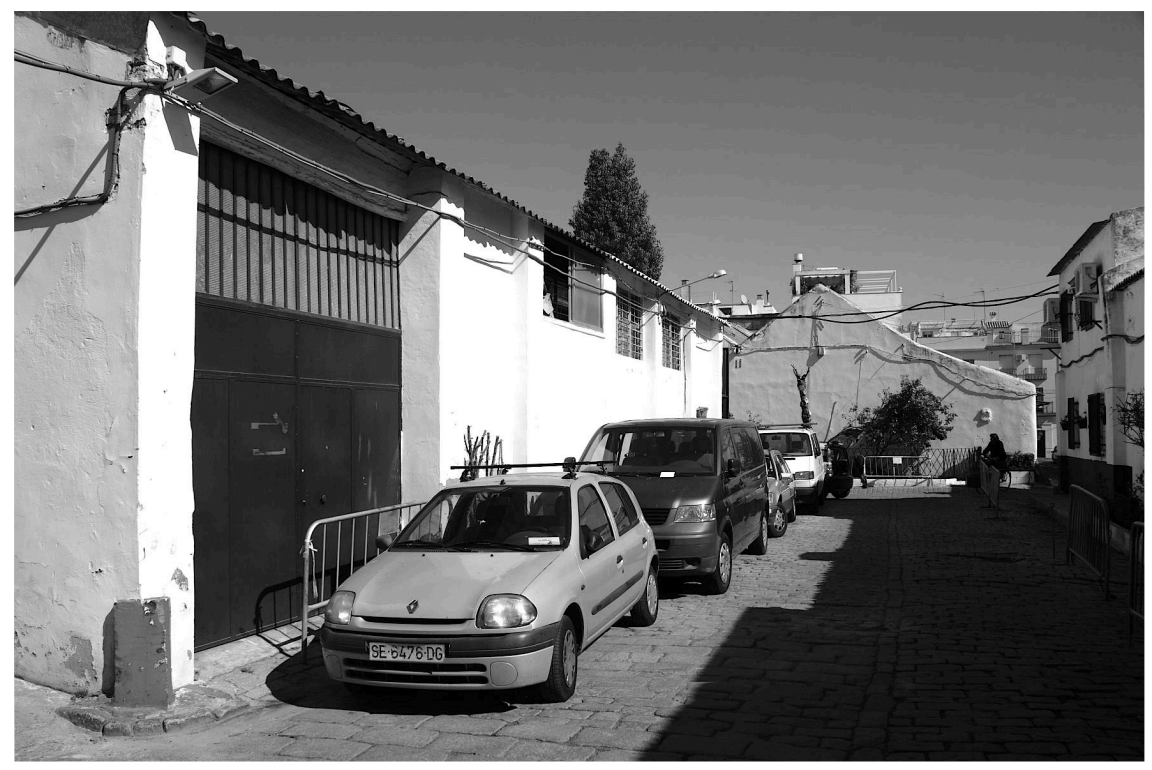

Figura 5. Calle interior del corralón de la plaza del Pelícano, 4.

Fuente: los autores (septiembre 2013).

automóviles, y da cabida a una docena de locales relacionados con actividades creativas. Algunos de ellos entroncan con labores tradicionales (como escultores o imagineros), pero la mayoría tiene que ver con estudios de música, danza o teatro; junto a ellos un espacio de coworking y una nave de formación circense.

En este lugar existe un continuo trasiego relacionado directa o indirectamente con las actividades que allí se desarrollan, lo que potencia su carácter como lugar de encuentro (artistas, visitas, alumnos de talleres...) y favorece una identidad propia, así como un sentimiento de pertenencia a una comunidad con señas particulares. La presencia de bicicletas (que es un signo de identidad en el casco norte) y otros elementos connotados completan y dan coherencia a la imagen de este lugar y de sus ocupantes. Se confirma pues una visibilidad media de las actividades creativas; no tanto por la imagen externa de los locales en sí, sino por el ambiente que se ha creado en su entorno.

\section{c) Rompemoldes}

Este edificio es un nodo singular dentro del casco norte, y no tanto por ser producto de las dinámicas que se han decantado en el barrio, sino por tratarse de una iniciativa municipal que, habiendo entendido la importancia del fomento de las actividades creativas, ha llevado a cabo una operación de alquiler conjunto de viviendas y talleres a precios muy ventajosos para artesanos con, al menos, una mínima trayectoria profesional. Se distingue del resto del barrio porque el concepto de partida es distinto y, en consecuencia, la morfología y el carácter 


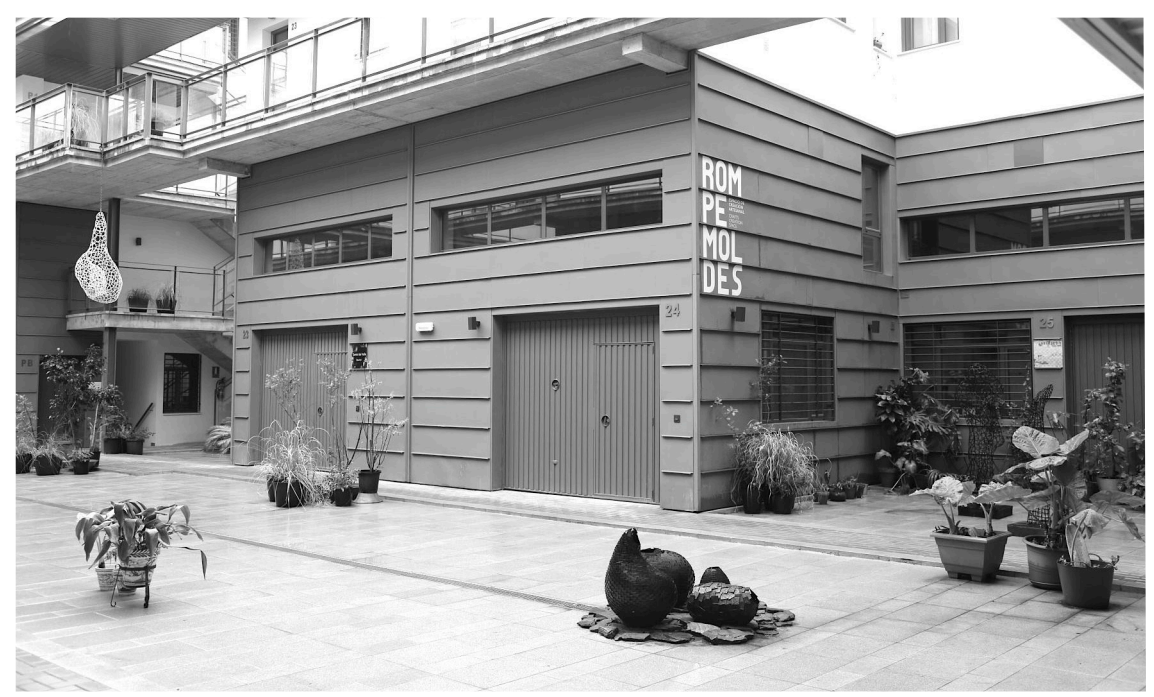

Figura 6. Patio central del edificio municipal Rompemoldes.

Fuente: los autores (noviembre 2013).

del edificio también lo son. Se trata de un antiguo inmueble que ocupaba una amplia parcela en el número 70 de la calle San Luis inserto en un potente contexto monumental, aunque a la puertas de uno de los entornos más degradados del centro histórico hasta hace tres decenios. Con el programa URBAN esta situación cambió y hoy esta calle es un eje principal del sector y una vía estratégica para valorizar un patrimonio cultural todavía poco reconocido.

La elección del solar (además de la oportunidad que suponía su titularidad municipal) se explica más por la pretensión de mejorar y aumentar el valor inmobiliario del barrio, y en consecuencia su contenido social, que por una estrategia global y coherente del Ayuntamiento por reforzar las actividades creativas ${ }^{2}$.

El proyecto incluye una treintena de talleres-tienda en la planta baja, estructurada por un largo y amplio espacio central abierto (Figura 6). Los artesanos-vecinos disponen de garaje en el subterráneo y de vivienda en las plantas altas. Las actividades son muy variadas: artistas plásticos, ceramistas, orfebres, diseñadores de moda, etcétera, junto con otras propuestas más heterogéneas.

El ambiente es tranquilo y se aprecia el uso doméstico que algunos de los inquilinos otorgan al patio (presencia de bicicletas, juguetes, asientos, flores...).

2. Algunas iniciativas institucionales previas sí han mostrado cierto interés en atender a las peculiaridades sociourbanísticas de este sector, como la ubicación de la primera sede de Proyecto Lunar (proyecto de incubadora y dinamización de empresas creativas) en el entorno de la Alameda de Hércules. Paradójicamente y al mismo tiempo, el Ayuntamiento de la ciudad alienta el desplazamiento de artesanos relacionados con la Semana Santa (tan definitorios del carácter de esta parte del casco norte) a un parque industrial de nuevo cuño (parque industrial de Arte Sacro) en la periferia norte de la ciudad. 
Sin embargo, y pese al sesgo creativo de los locales, se trata de un ambiente menos espontáneo que el de otros lugares presentados y refleja una identidad impostada o, al menos, en consolidación.

En este caso, la arquitectura es coherente con el mensaje que se pretende dar: una parcela vaciada, de la que solo se conserva la fachada, y un interior de arquitectura con pretensiones de singularidad que acentúa la visibilidad de las actividades creativas.

\subsection{Ejes}

a) Regina

La calle Regina es un eje viario arquetípico de las calles comerciales peatonales tradicionales de Sevilla. Se encuentra en el margen norte del centro comercial y, como otros espacios de entrada a este centro, observó un estancamiento y decadencia desde los años setenta del siglo pasado por la competencia de los grandes almacenes y las tiendas franquiciadas. Se produjo así una fosilización comercial para segmentos de demanda muy definidos y con escaso poder adquisitivo.

Desde finales del siglo xx, la saturación del proceso señalado y las ventajas en la accesibilidad de algunos de estos ejes al centro comercial promueven un modelo de establecimientos pequeños, pero con mercancía singularizada por su diseño o carácter (Figura 7), que han recuperado, aunque sea parcialmente, la centralidad perdida.

En el caso de la calle Regina, esta circunstancia se acentúa por arrancar de la base de uno de los proyectos estrella del Ayuntamiento, y también de los más contestados por su forma y coste durante los últimos años: el proyecto MetrosolParasol en la plaza de la Encarnación. En la actualidad, en esta pequeña calle alterna una decena de locales relacionados con actividades creativas (moda, muebles de diseño, librería imaginativa, etcétera) con otros que mantienen un uso y una apariencia tradicionales (tejidos de hogar, mobiliario...). Esto provoca que la visibilidad de la actividad relacionada con la creatividad sea más evidente, ya que el diseño de estos locales contrasta sensiblemente con su entorno.

La calle Regina mantiene su carácter de acceso al centro de la ciudad y comparte la indefinición que tienen los ámbitos de transición; pero al mismo tiempo es un lugar muy transitado, muy ligado a los mapas mentales locales (conecta el mentado centro urbano con la tradicional calle Feria) y en el que se ha consolidado también un uso hostelero que alterna tradición y diseño. Esta calle es, pues, un eje comercial heterogéneo, con una visibilidad media-alta de las actividades creativas, las cuales han recontextualizado esta vía respecto al centro comercial de la ciudad.

\section{b) Correduría}

La calle Correduría comparte muchos aspectos con la calle Regina, aunque su relativo apartamiento del centro comercial y, al contrario, su papel de puente entre la Alameda y la calle Feria (eje comercial tradicional de barrio), le confieren un carácter especial. Esta calle también acusó el estancamiento y la 


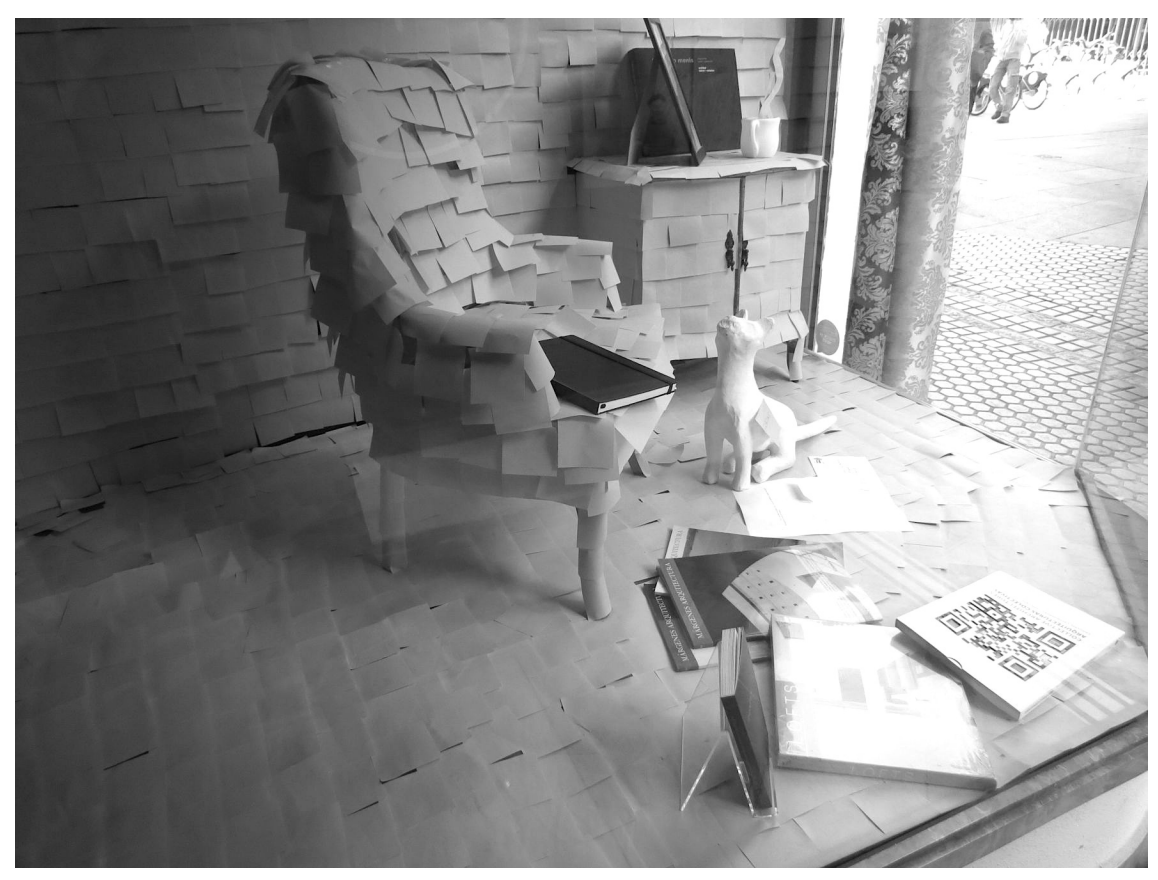

Figura 7. Escaparate de la librería Un gato en bicicleta de la calle Regina.

Fuente: los autores (noviembre 2013).

regresión del comercio y de la hostelería tradicionales, hasta el punto de que, si bien es una calle transitada, sus locales pasaron por un patente proceso de decadencia. A su carácter no peatonal hay que añadir el tránsito, pese a su relativa estrechez, de autobuses urbanos, lo que la convierten en una calle incómoda para el viandante.

Durante los últimos años, y especialmente tras la implementación del proyecto URBAN y los cambios en la vecina Alameda, se han abierto algunos comercios que enriquecen el contenido funcional de la vía a partir de actividades ligadas a la creatividad: decoración, artesanía, arte y antigüedades. A esto se suma también la apertura de nuevos locales hosteleros (Figura 8) y la aparición de algún inmueble con diseño arquitectónico de claves modernas. Es pues un eje de tránsito sin una identidad definida, aunque enlaza dos sectores que han reforzado su imagen y carácter (Alameda y Feria). La visibilidad de las actividades creativas es baja, pero están en la base de los cambios cuantitativos y cualitativos de este eje.

\section{3. Ámbitos}

a) Alameda

La Alameda de Hércules, junto a la renovación de la Encarnación y a la reconstrucción del barrio de San Luis, son los espacios intramuros que más cambios 


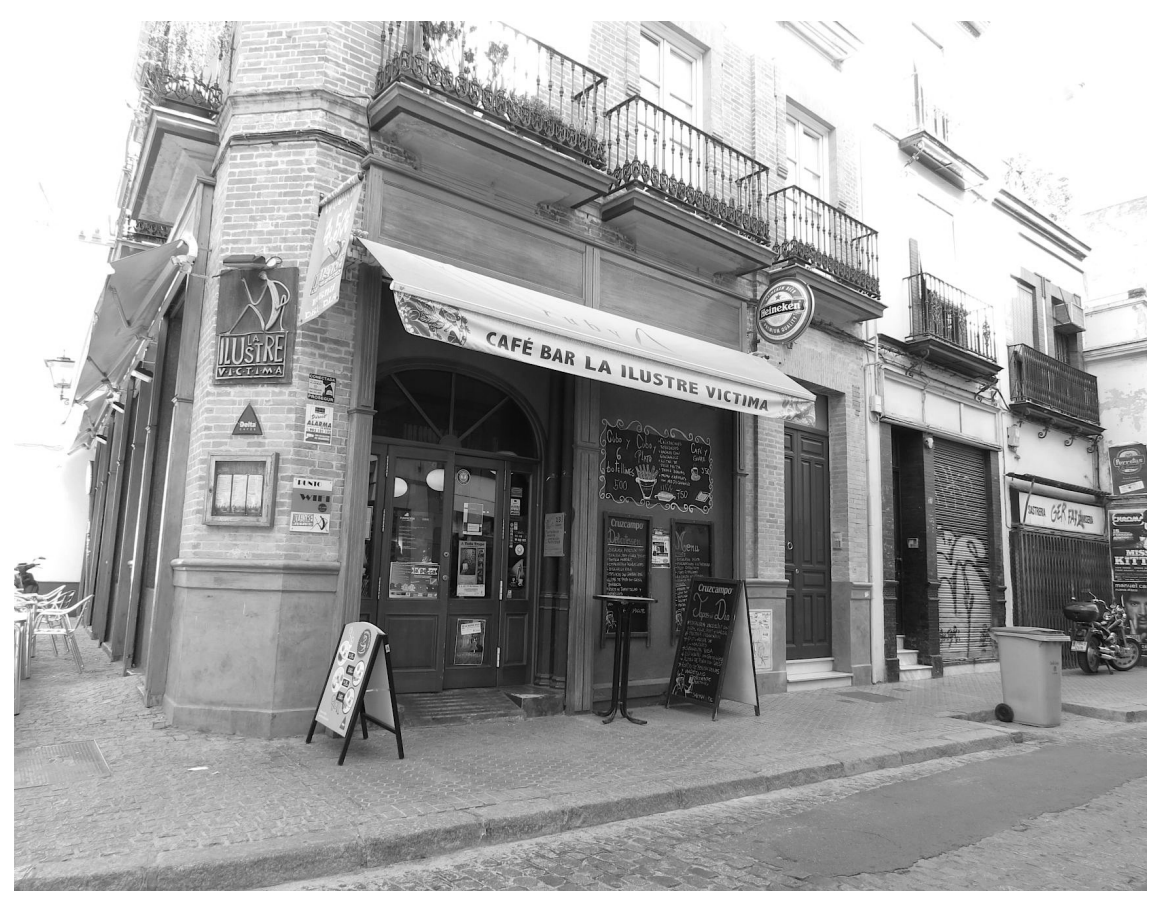

Figura 8. Vista exterior del café-bar La ilustre víctima, en la calle Correduría.

Fuente: los autores (enero 2013).

han experimentado en los últimos decenios. La Alameda se construye en el siglo XVI y ha pasado por todo tipo de avatares históricos hasta el punto de convertirse, antes de su renovación, en un aparcamiento informal y lugar de referencia de prostitución y menudeo de droga. Las dinámicas impulsadas por el proyecto URBAN cambiaron esta situación creando una nueva configuración formal de este espacio, no suficientemente afortunada para su carácter histórico, pero que, desde el punto de vista funcional, ha dignificado el sector.

Las consecuencias de este proceso han sido muy variadas: a) la renovación formal y un nuevo concepto de control del tráfico y de espacios peatonales; b) la regeneración funcional, constituyendo la Alameda el principal nodo de ocio nocturno de la ciudad. Gran cantidad de bares, locales musicales, restaurantes y otros lugares de encuentro y sociabilidad se disponen en torno a este espacio urbano y calles adyacentes, junto a otros establecimientos de comercio o servicios creativos. Se trata de un contexto con abundantes lugares de carácter alternativo, locales de sesgo gay o espacios de diseño que atraen a un público variado pero que valora formas de expresión poco convencionales, en algunos casos hasta el esnobismo. De algún modo, la consolidación como espacio de ocio es la expresión actual de un pasado reciente más transgresor; y c) la renovación del parque residencial del sector, muy profunda desde los 


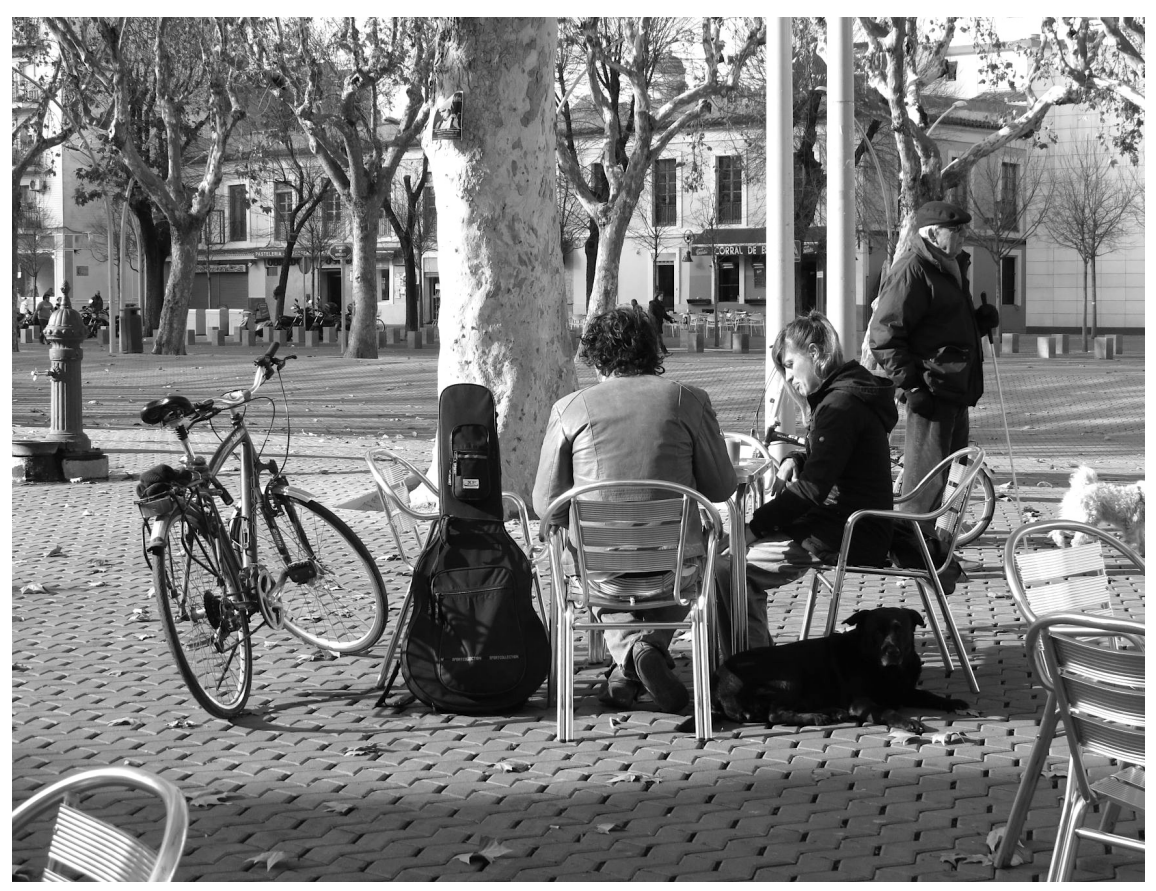

Figura 9. Terraza en la Alameda de Hércules.

Fuente: los autores (octubre 2013).

años noventa, y que ha generalizado la aparición de edificios de viviendas y apartamentos que permiten hablar de gentrificación y de atracción, también, de un perfil de residente que, además de lo expuesto, valora la mezcla entre vecinos y usos tradicionales (ambos en franca regresión desde hace decenios) en la forma de identificarse con su barrio.

Como consecuencia de ello, la Alameda es un sector profundamente renovado, tanto en los espacios públicos como en los privados, que se ha dotado de una imagen diferencial en el diseño y que se connota por su propio uso y apropiación social. Su oferta cultural y creativa es dinámica, lo que da sentido a distintos escenarios de uso. Así, si el arbolado, la morfología o las columnas son vectores de potencia patrimonial, las personas o las bicicletas lo son de su apropiación y reconocimiento actual (Figura 9).

\section{b) Pumarejo}

El Pumarejo es un ámbito que posee como referentes el palacio y la plaza homónimos, construidos ambos en el último tercio del siglo xviII. Con la proletarización de buena parte del casco norte sevillano en la segunda mitad del siglo XIX y los primeros decenios del xx, el antiguo palacio, se convirtió en casa de vecinos y, tras medio siglo de vaciamiento residencial, este inmueble 


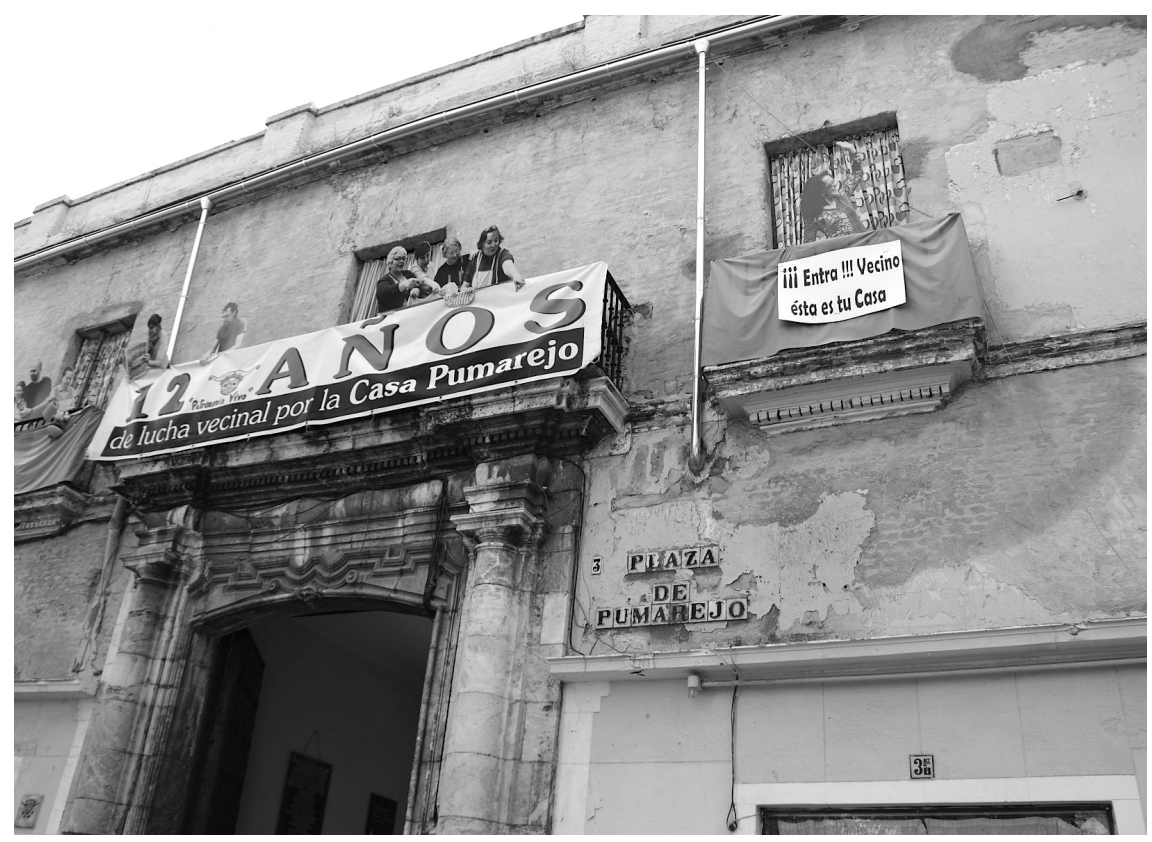

Figura 10. Fachada del palacio del Pumarejo.

Fuente: los autores (octubre 2013).

se ha convertido en testigo de una tipología prácticamente desaparecida y en la que la lucha de los vecinos por mantenerse en su domicilio tradicional ha adquirido una importante resonancia simbólica de resistencia, alternativa y antisistema (Figura 10).

El entorno del edificio se ha convertido en un espacio complejo donde aún se mantiene un cierto carácter marginal (ha sido un lugar tradicional de menudeo de droga), al que se ha proyectado la simbología del edificio, y en el que también ha entrado el carácter de renovación señalado para la Alameda. Así, han aparecido restaurantes, lugares de ocio, actividades formativas y una oferta cultural nueva, en parte en instalaciones del propio palacio.

La visibilidad de las actividades creativas se mezcla con el carácter reivindicativo de los grupos asociados a estos espacios y que generan también manifestaciones explícitas de apropiación de los espacios públicos. Pese a ser un ámbito reducido, el imaginario del Pumarejo también ha trascendido el centro histórico y posee una amplia proyección en la ciudad. El carácter histórico de este ámbito y sus significados contestatarios actuales son más potentes que en la Alameda, siendo parte esencial de este imaginario el compromiso con los valores tradicionales del barrio. En el entorno de la plaza estas referencias atraen locales expositivos o comerciales más o menos alternativos, coherentes con el nuevo perfil de vecino y visitante. 


\section{Conclusiones}

\section{a) Generales}

La atracción de actividades creativas es un proceso complejo, que presenta siempre características peculiares en cada espacio en el que se consolidan y cuyo impulso no responde a mecanismos lineales, sino a la interacción en el espacio urbano de las lógicas globales y locales. En las grandes metrópolis, dada su masa crítica y su papel preponderante en el territorio, las lógicas de las actividades creativas suelen entroncar, tanto con una tradición intelectual y artística, como con nuevas formas de expresión cultural consolidadas con la globalización, especialmente en lo que concierne al diseño, los nuevos significados del patrimonio o, simplemente, por unos ritmos y dinámicas diferentes en la conformación de los gustos y, en consecuencia, de las demandas de las poblaciones urbanas. Sea por un hecho o por el otro, las actividades creativas son un hecho inherente a todas las ciudades que se sitúan en un lugar privilegiado y visible del mundo globalizado.

Pero pese a esta preponderancia de la gran ciudad como polo de atracción de estas actividades, no debe minusvalorarse su papel en ciudades no reconocidas en la escala global como referentes de creatividad. También en ellas explican procesos, paisajes e imaginarios que ofrecen pistas para encarar en la escala local las difíciles circunstancias del nuevo y actual proceso de reestructuración socioeconómica.

La imagen de la creatividad, también frente a los estereotipos, es una imagen diversa, cambiante y que debe ser interpretada, no solo a través de procesos globales, sino también en razón del carácter propio, singular e irrepetible de cada ciudad. Al entroncar con actividades previas o al imponerse a procesos que reelaboran las realidades urbanas (sociales, culturales, económicos, físicos o políticos), los escenarios e imaginarios a los que dan lugar también son de carácter muy diverso. Los paisajes identitarios de la ciudad, en continua construcción y cambio, ayudan a comprender cómo desde los escenarios cotidianos y su apropiación colectiva se alcanzan imaginarios que se proyectan, y proyectan a la ciudad en general, a la escala global conformando identidades locales pero que son también susceptibles de ser entendidas y compartidas como una etiqueta de calidad urbana. Asumir esto ayuda a comprender por qué las fórmulas para alentar las actividades creativas son difícilmente extrapolables de unas ciudades a otras y cómo su comprensión no puede desligarse del análisis del entorno y de trayectorias locales propias.

A este respecto, cabe señalar que las actividades creativas están presentes en las ciudades desde tiempo inmemorial. El propio concepto de ciudad se liga, más que a realidades físicas concretas, al control e impulso de la innovación y la creatividad. Es pues importante conocer cada trayectoria urbana para favorecer estas actividades que, con pautas y características también nuevas, no solo explican el desarrollo urbano de las ciudades primaciales globales, sino también la transformación de realidades urbanas en ciudades que no son referentes mundiales de estas actividades. 


\section{b) Respecto a las actividades creativas en Sevilla}

Sevilla es una ciudad con una larga trayectoria de expresiones culturales diversas (artistas, literatos, patrimonio en sus más variadas tipologías), pero su condición de capital de una región con graves problemas para impulsar procesos de desarrollo le ha proporcionado un papel secundario entre las ciudades de referencia para la modernidad y, en general, un marcado sesgo tradicional de sus actividades creativas. Sin embargo, los procesos innovadores también son aquí perceptibles y tienen que ver más con procesos orgánicos que con los planificados por instituciones públicas y privadas, aun con excepciones.

Las actividades creativas del casco norte poseen una variada ubicación, pero en no pocos casos relacionada con importantes rasgos de marginalidad hasta los años noventa. Las operaciones de reforma urbana a partir de fondos europeos URBAN y la sustitución generacional de los antiguos vecinos tradicionales un proceso lento y que aún no ha periclitado - han configurado un complejo mosaico social que, manteniendo fórmulas de creatividad tradicionales (imagineros, artistas plásticos, talleres artesanos), ha sido especialmente atractivo para nuevos creadores, tanto desde el punto de vista residencial como funcional. Procesos de gentrificación, sectores contestatarios, cultura gay, población y actividades tradicionales hacen del casco norte un espacio en cambio continuo que contrasta con el casco sur: el sector proyectado internacionalmente, sede de instituciones de prestigio social, fuerte carga patrimonial y centro comercial tradicional; pero que desde el punto de vista de la creatividad no ofrece, ni lejanamente, el mismo interés.

Del ejemplo de Sevilla, se puede concluir que el asentamiento de actividades creativas alentado de arriba abajo se relaciona más con el cambio de imagen que con una renovación profunda del concepto creativo; mientras que, de abajo arriba, este asentamiento, junto con otros factores, genera identidades y apropiaciones físicas y simbólicas, aunque no cambios potentes de imagen.

Las dinámicas creativas y las distintas manifestaciones en las que se materializan son causa y efecto de transformaciones urbanas que son esenciales para comprender qué es y qué significa el casco norte de Sevilla hoy. Asimismo, las referencias creativas son parte consustancial del nuevo imaginario que se reconoce en este sector y que se proyecta al resto de la ciudad, constituyendo un paisaje que no es continuo ni siempre evidente, pero sí de gran interés y potencia por lo que aporta al carácter de la ciudad.

\section{c) Respecto a los espacios de referencia de las actividades creativas en el casco norte}

Sin embargo, tampoco el casco norte es un espacio creativo homogéneo, ni en lo que respecta a la distribución de las actividades creativas, ni en lo relativo a sus tipologías. Los espacios más relacionados con las reformas del plan URBAN, Alameda de Hércules y entorno, explican un cambio de imagen en el paisaje urbano potente, que arranca de los espacios públicos y se expande a edificios y locales, siendo dinamizado por grupos sociales próximos a 
una suerte de bohemia gentrificadora (jóvenes de clase media atraídos por un ambiente cultural y de ocio renovado). Por su parte, el entorno de la calle San Luis, Pumarejo o los corralones del Pelícano y Castellar, son espacios menos transformados en su paisaje urbano, pero con una mayor renovación de las actividades creativas: especialmente aquellas que suponen nuevos modelos de organización o algunas relacionadas con sectores tradicionales: imaginería y flamenco sobre todo.

La pervivencia de pautas tradicionales y aún vivas es un aspecto que resulta atractivo para los nuevos creadores. Por un lado está la apropiación del carácter de autenticidad de este entorno (calles y plazas, vecinos y locales) y, de otro, lo que podría llamarse factor sorpresa en el paseante al encontrar locales de un carácter innovador (cartelería, mobiliario y, sobre todo, decoración) en un entorno tradicional.

Mención especial merece el papel que asume el interior de algunos inmuebles (sobre todo Pelícano, 4; pasaje Mallol, 8; y Castellar, 52) que, pese a su carácter privado, funcionan como espacios públicos: no existen barreras en la entrada, poseen locales comerciales, artesanales y de otros usos culturales y terminan funcionando como pequeñas calles y plazas. Su imagen no presenta un cambio notable respecto a la que mostraban hace algunos años, pero desde un punto de vista cualitativo los cambios son importantes ya que incorporan nuevos significados a los espacios de sociabilidad del barrio, enraizados con una tradición ya existente (y que atañía tanto a lo residencial — corrales y patios—, como a las actividades - corralones-), pero con un carácter nuevo y favorable a la creación de conexiones y redes entre creativos.

En cuanto a los ejes que concentran actividades creativas, la calle Feria mantiene su significado tradicional, mientras que otros, como Correduría y, sobre todo, Regina, muestran cambios, no tanto en la configuración de sus espacios públicos o arquitectónicos, sino en el carácter de algunos locales comerciales, todos ellos mezclados con otros de cuño tradicional.

La única intervención institucional relacionada con el asentamiento de creativos en el casco norte (Rompemoldes), posee una imagen renovada y original; aunque, por el contrario, no ha conseguido de momento el desarrollo de redes o fórmulas de cooperación internas trascendentes.

\section{Referencias bibliográficas}

Almuedo, José (1996). Ciudad e industria. Sevilla 1850-1930. Sevilla: Diputación de Sevilla.

Aplin, Graeme (2007). «World Heritage Cultural Landscape». International Journal of Heritage Studies, 13 (6), 427-446. $<$ http://dx.doi.org/10.1080/13527250701570515>.

Barber, Santiago; Fresel, Victoria; y Romero, M. José (coords.) (2006). De cómo nació, creció y se resiste a ser comido. El gran pollo de la Alameda, una docena de años de lucha social en el barrio de la Alameda, Sevilla. Sevilla: Publigrupo.

Baumont, Catherine y Boiteux-Orain, Céline (2005). Secteur culturel, metropolisation et centralites urbaines. Le cas de l'Ile-de-France. Dijon: Université de Bougogne. 
Bayliss, Darrin (2007). "The Rise of the Creative City: Culture and Creativity in Copenhagen». European Planning Studies, 15 (7), 889-903. <http://dx.doi.org/10.1080/09654310701356183>.

Berdoulay, Vincent (2002). «Sujeto y acción en la geografía cultural: el cambio sin concluir». Boletín de la Asociación de Geógrafos Españoles, 34, 51-61.

BorJa, Jordi (2008). "El urbanismo de las ciudades creativas: entre el azar y la necesidad». En: Manito, Félix. Ciudades creativas. Cultura, territorio, economía y ciudad. Zaragoza, Kreanta.

BrInkHOFF, Sascha (2006). «Spatial Concentration of Creative Industries in Los Angeles», Berlín: Diplomarbeit, Humboldt-Universität zu Berlin Geographisches Institut.

Cantero, Pedro A. et al. (1999). La ciudad silenciada: vida social y Plan Urban en los barrios del Casco Antiguo de Sevilla. Sevilla: Ayuntamiento de Sevilla.

Caravaca, Inmaculada, González, Gema, Fernández, Víctor y García, Antonio (2011). «Economía creativa en la aglomeración metropolitana de Sevilla: agentes, redes locales de colaboración y principales actuaciones». Boletín de la Asociación de Geógrafos Españoles, 63, 81-103.

Caravaca, Inmaculada, González, Gema y García, Antonio (2011). «Nuevas tendencias socioeconómicas en los espacios urbanos. Las actividades creativas en la aglomeración metropolitana de Sevilla». En: Gozálvez, Vicente y Marco, Juan A. (coords.). Urbanismo expansivo: de la utopía a la realidad. Alicante: Asociación de Geógrafos Españoles, 103-118.

Cassián, Nizaiá (2012). "De qué está hecha una ciudad creativa. Una propuesta para abordar la cultura, el ocio y la creatividad en la urbe contemporánea». Athenea Digital, 12 (1), 169-190.

Cooke, Philip y Lazzeretti, Luciana (eds.) (2008). "Creativity, innovation and territorial agglomeration in cultural activities: the roots of the creative city». Creative Cities, Cultural Clusters and Local Economic Development. Cheltenham-Northamton: Edwaerd Elgar.

Costa, Pedro (2008). «Creativity, innovation and territorial agglomeration in cultural activities: the roots of the creative city». En Cooke Philip y Lazzeretti, Luciana (eds.). Creative Cities, Cultural Clusters and Local Economic Development. Cheltenham-Northamton: Edwaerd Elgar, 183-211.

Currid, Elizabeth (2007). The Warhol Economy. How Fashion, Art and Music drive New York City. Princeton: Princeton University Press.

DíAz, Ibán (2014). «La gentrificación, un regreso a la ciudad de la intervención urbanística». Boletín de la Asociación de Geógrafos Españoles, 64, 321-340.

Evans, Graeme (2009). "Creative cities, creative spaces and urban policy». Urban Studies, 46 (5-6), 1003-1040. <http://dx.doi.org/10.1177/0042098009103853>.

Florida, Richard (2005). Cities and the Creative Class. Nueva York y Londres: Routledge.

- (2012). "The spiky world of innovation», Citylab From The Atlantic. <http:// www.citylab.com/work/2012/04/spiky-world-innovation/1592/> [consulta: 11 de diciembre de 2014].

Freeman, Alan (2005). London's Creative Sector: 2007 Update. Londres: GLA Economics Working Paper 22. <https://www.london.gov.uk/sites/default/files/gla_ migrate_files_destination/wp_22_creative.pdf> [consulta: 1 de mayo de 2014].

Galimberti, Cecilia Inés (2011). «Paisaje cultural y región. Una genealogía revisitada...». GeoGraphos, 54 (4), 531-552. <web.ua.es/es/revista-geographos-giecryal/ 
documentos/cecilia-galimberti.pdf?no-Cache $=1372936293003>$ [consulta: 25 de abril de 2014].

García, Antonio; Fernández, Víctor; Caravaca, Inmaculada y González, Gema (2012). "Cultural resources and creative industries in Spanish medium-sized cities». Brazilian Geographical Journal: Geosciences and Humanities Research Medium, 3 (1), 50-69.

GiL, Carmen (2010). "Capitales culturales europeas. El concepto europeo de cultura en relación con algunos procesos actuales de renovación simbólica y de transformación urbana». Scripta Nova. Revista Electrónica de Geografia y Ciencias Sociales, XIV (339). <http://www.ub.edu/geocrit/sn/sn-339.htm> [consulta: 2 de mayo de 2014].

Gill, Rosalind (2007). Technobohemians or the new Cybertariat? New media work in Amsterdam a decade after the web. Ámsterdam: Network Notebooks 01, Institute of Network Cultures.

GonZÁLEZ, Antonio (2001, primera edición en 1975). Sevilla: centralidad regional y organización interna de su espacio urbano. Madrid: Servicio de Estudios del Banco Urquijo.

JacoBs, Jane (2004). Dark Age Ahead. Nueva York: Random House.

Johansson, Börje (2010). Creative Milieus in the Stockholm Region. Estocolmo: KTH, Skolan för industriell teknik och management (ITM), Centra, Centrum för studier inom vetenskap och innovation, CESIS.

KnEll, John y OAKLEY, Kate (2007). London's Creative Economy: An Accidental Success? Provocation Series 3 (3). Londres: The Work Foundation.

Landry, Charles (2000). The Creative City: A Toolkit for Urban Innovators. Londres: Earthscan.

LAZZERETTI, Luciana (2007). «Culture, creativity and local economic development: some evidences from creative industries in Florence». En: Cooke, Philip y Schwartz, Dafna (eds.). Creative Regions; Technology, Culture and Knowledge Entrepeneurship. Cheltenhalm (Reino Unido) y Norhtampton (Estados Unidos): Edgar Elgar, 169-196.

Lloyd, Richard (2010). Neo-Bohemia: Art and Commerce in the Postindustrial City. Londres: Routledge.

Liegooghe, Christine y Lusso, Bruno (2010). «Creativity and former industrial cities: The case of the Lille metropolitan area (North of France)». Regions Magazine, 277(1), 21-23.

Maderuelo, Javier (ed.) (2010). Paisaje y patrimonio. Huesca/Madrid: CDAN, Abada Editores.

Moriset, Bruno (2003). "The New Economy in the City: Emergence and Location Factors of Internet-based Companies in the Metropolitan Area of Lyon, France». Urban Studies, 40 (11), 2165-2186. <http://dx.doi.org/10.1080/0042098032000123231>.

Murphy, Enda y ReDMOND, Declan (2008). Location factors of creative knowledge companies in the Dublin Region The managers' view. Ámsterdam: Amsterdam institute for Metropolitan and International Development Studies (AMIDSt), University of Amsterdam.

NoguÉ, Joan (2010). «El retorno del paisaje». Enrahonar. Quaderns de Filosofia, 45, 123-136. <http://itpack31.itarget.com.br/uploads/anp/arquivos/paisaje2010-JoanNogue.pdf> [consulta: 11 de diciembre de 2014].

OJeDA, Juan Francisco (2013). «Lectura transdisciplinar de paisajes cotidianos, hacia una valoración patrimonial. Método de aproximación». Revista Invi, 28 (78). <http://revistainvi.uchile.cl/index.php/INVI/article/view/803/1095> [consulta: 14 de abril de 2014]. 
PAüL, Daniel (2013). «Las políticas culturales y sus repercusiones en la imagen de la ciudad». Scripta Nova. Revista Electrónica de Geografía y Ciencias Sociales, XVII (432). <http://www.ub.edu/geocrit/sn/sn-432.htm> [consulta: 22 de abril de $2014]$.

Pratt, Andy (2008). «Creative Cities?». Urban Design, 106, 35-60.

Skazzosi, Lionella (2004). "Reading and assessing the landscape as cultural and historical heritage». Landscape Research, 29 (4), 335-355. <http://dx.doi.org/10.1080/0142639042000288993>.

UnCTAD (2008). Creative economy report. The challenge of assessing the creative economy: towards informed policy-making. Washington DC: UNCTAD. 